XI._On a Case of Colour Blindness. By WM. Peddis, D.Sc. (With a Plate.)

PART I.*

(Read 7th January, 18th February, and 3rd June 1895.)

\title{
Introduction.
}

The case under consideration was brought to my notice while I was attempting to arrange a colour match by the well-known disc method. The colour was somewhat like lilac, though rather more red. A number of onlookers-including the gentleman whom I afterwards found to be colour-blind, and whom I shall in this paper denote as $\mathrm{Mr} \mathrm{A}$.pronounced the match fairly satisfactory. Mr A. subsequently remarked to me that he sometimes had a difficulty in distinguishing greens and blues. He said, also, that he had, though much less frequently, a difficulty with reds. This condition is so abnormal that I at once handed him a direct vision spectroseope and asked him to name the colours which he saw in succession from one end of the spectrum to the other. He said that red was the first. "And after the red?"I asked; "green," he said : "and after the green ?"; "blue." And when asked what followed the blue, he said that the rest of the spectrum was blue throughout the whole extent. When asked if he saw white light between the red and green colours, he was very undecided, but said that he did not think he would call it white-it might be yellow.

Except for the fact that green and blue were distinguished in the spectrum, the case seemed most like one of blindness to yellow and blue, or "violet-blindness" as it was termed on the original Young-Helmholtz theory.

Next day I showed Mr A. the spectrum formed by a more powerful instrument which gave such dispersion that only about one-quarter of the length of the spectrum could be seen at one time. I asked him to adjust, if be could, the wires to a part which seemed colourless to him. The part which he marked was near the line $D$ on the more refrangible side. I asked him to move the spectrum across the field of vision towards the more refrangible end and name the colours as they passed the centre of the field. He said that there was only one colour, which he called red. The point of strongest red colour he placed near the line $\mathrm{C}$ on the less refrangible side, and the spectrum was visible throughout the full normal range towards the red end. In the same way, all the range of the spectrum on the more refrangible side of the neutral point was said to be of one colour, which was called blue. The point of maximum colour was placed between the lines $b$ and $\mathrm{F}$-rather nearer the latter than midway between them-and the spectrum was visible to the full normal range

* This part contains results communicated to the Society as follows:-Introduction, 7th January 1895 ; comparison with the case deseribed by v. VintschgaU and Hering, 18th February 1895; and the rest, 3rd June 1895.

VOL. XXXVIII. PART II. (NO. I1). 
beyond the lines $\mathrm{H}$. I asked $\mathrm{Mr}$ A. if he would be as well satisfied in calling that half of the spectrum green, and he said that he would be so.

From the preceding observations, it seemed that the case was one of red-green vision or of blindness to yellow and blue. But there was this striking peculiarity-that Mr A., if he were asked to place the cross wires at the extreme limit of vision at either end of the spectrum, invariably placed them at points corresponding to full normal vision; whereas, in all cases of yellow-blue or "violet" blindness hitherto described-so far as I know-the blue end of the spectrum is considerably shortened, and sometimes the red end is shortened also.

I then showed Mr A. the two complementarily-coloured images which are produced by passing plane polarised light through a plate of quartz and a double-image prism and asked him if he could make the colours alike by rotating the prism. He said that it was impossible for him to do so. The quartz was of such a thickness that the complementary colours were, on the whole, reddish and greenish respectively. I then replaced the quartz by a thinner plate, which gave bluish and yellowish complementary colours, and he said that he could then get equality. The colours which he asserted to be alike were a pale blue and a pale straw colour respectively. This verified the conclusion that the case is one of blindness to yellow and blue.

On the other hand, when the thicker quartz plate was used, I asked Mr A. if he could make one of the images colourless? He replied, with some hesitation, that he could; and I was somewhat surprised to find that the colour then was a strong blue-green. This seemed to indicate considerable weakness in the green sensation.

I next showed Mr A. a dark blue, strongly-coloured powder. He said that it was almost black, and he remarked also that a dark blue sky seemed almost black to him. A strongly-coloured yellow powder he pronounced to be almost colourless. Subsequently, I showed him an intimate mixture of these two powders, which was distinctly of a green colour though it was greyish, and he said that it also had no colour.

\section{Colour-Disc Tests.}

Colour equations were then obtained in the usual manner by means of the rotation of coloured discs. These are given below. The numbers, as usual, represent the angular measure of the various coloured sectors. The symbols $R, Y, G, B, B k, W$, represent respectively red, yellow, green, blue, black, and white. The red was a strong scarlet, containing some yellow; the green was a strong emerald green, containing some yellow; and the blue was Prussian blue, though somewhat dull in tone. The yellow might be called pure.

Limits between which the true match lay were taken. Thus, when a green disc was matched with black and white, the limiting results were

$$
\left.\begin{array}{l}
360 \mathrm{G}=130 \mathrm{~W}+230 \mathrm{Bk} \\
360 \mathrm{G}=110 \mathrm{~W}+250 \mathrm{Bk}
\end{array}\right\}
$$


If less white than 110 was taken, the grey was too dark; if more than 130 was taken, the grey was too light. Thus green can be matched with grey. Yet it should be noted that $\mathrm{Mr}$ A. always said that he was not satisfied with this match because the grey disc had a red tinge. This red tinge was quite obvious to the normal eye and was apparently due to the contrast with the strong green colour. It appeared whether a small green disc was placed on large black and white sectors or small black and white sectors were placed on a large green disc, i.e., whether the green colour was at the centre, or the circumference, of the compound disc. The conclusion is that green, though it does not produce a distinct colour impression, yet can, by contrast, give rise to the complementary colour sensation. This point is considered farther below.

In the same way, with the blue disc, the equations

$$
\left.\begin{array}{l}
360 \mathrm{~B}=132 \mathrm{~W}+228 \mathrm{Bk} \\
360 \mathrm{~B}=112 \mathrm{~W}+248 \mathrm{Bk}
\end{array}\right\} \quad \cdot \quad \cdot \quad . \quad \mathrm{II}
$$

were obtained-the match being quite satisfactory.

Again, a mixture of blue and green gave

$$
\left.\begin{array}{l}
180 \mathrm{~B}+180 \mathrm{G}=127 \mathrm{~W}+233 \mathrm{Bk} \\
180 \mathrm{~B}+180 \mathrm{G}=120 \mathrm{~W}+240 \mathrm{Bk}
\end{array}\right\} . \quad \text { III }
$$

A mixture of red and green gave

$$
\left.\begin{array}{l}
174 \mathrm{R}+186 \mathrm{G}=91 \mathrm{~W}+269 \mathrm{Bk} \\
174 \mathrm{R}+186 \mathrm{G}=87 \mathrm{~W}+273 \mathrm{Bk}
\end{array}\right\} \quad \cdot \quad \mathrm{IV}
$$

a sufficient amount of green being taken to entirely destroy the red. A similar experiment with blue and red gave

$$
\left.\begin{array}{l}
75 \mathrm{R}+285 \mathrm{~B}=114 \mathrm{~W}+246 \mathrm{Bk} \\
75 \mathrm{R}+285 \mathrm{~B}=95 \mathrm{~W}+265 \mathrm{Bk}
\end{array}\right\} . \quad . \quad \mathrm{V}
$$

And, when the blue in this match was replaced by the equivalent amounts of black and white, the match was at once destroyed, the mixture being called red by $\mathrm{Mr} \mathrm{A}$, and appearing distinctly red to the normal eye. This proves that the blue, which was matched with grey, possesses, in common with green, though to a less extent, the property of neutralising red.

By repeating observations on these several colour equations, and taking averages for each, a series of self-consistent equations might be found. But it is easy, without the labour involved in that method, to deduce a self-consistent set of equations lying well within the experimental limits. 
Thus write

$$
\begin{aligned}
360 \mathrm{~B} & =(112+p) \mathrm{W}+(248-p) \mathrm{Bk} & & p \ngtr 20 \\
360 \mathrm{G} & =(110+q) \mathrm{W}+(250-q) \mathrm{Bk} & & q \ngtr 20 \\
180 \mathrm{~B}+180 \mathrm{G} & =(120+r) \mathrm{W}+(240-r) \mathrm{Bk} & & r \ngtr 7
\end{aligned}
$$

and we get

$$
p+q=18+2 r
$$

Say, then, $r=3, p=11, q=13$, and we get

$$
\begin{aligned}
& 360 \mathrm{G}=123 \mathrm{~W}+237 \mathrm{Bk} \text {. . . . ( (I) } \\
& 360 \mathrm{~B}=123 \mathrm{~W}+237 \mathrm{Bk} \\
& 180 \mathrm{G}+180 \mathrm{~B}=123 \mathrm{~W}+237 \mathrm{Bk} \text {. . . }
\end{aligned}
$$

Similarly write-

$$
\begin{aligned}
174 \mathrm{R}+186 \mathrm{G} & =(87+\alpha) \mathrm{W}+(273-\alpha) \mathrm{Bk}, \quad \alpha \ngtr 4 \\
75 \mathrm{R}+285 \mathrm{~B} & =(95+\beta) \mathrm{W}+(265-\beta) \mathrm{Bk}, \quad \beta \ngtr 19
\end{aligned}
$$

and we get, by elimination of $R$ and the use of equations (I) and (II),

$$
\beta-0.431 \alpha=12
$$

If, therefore, we assume $\alpha=2, B=13$, we have

$$
\begin{array}{r}
174 \mathrm{R}+186 \mathrm{G}=89 \mathrm{~W}+271 \mathrm{Bk} . \quad . \quad \text { (IV) } \\
75 \mathrm{R}+285 \mathrm{~B}=108 \mathrm{~W}+252 \mathrm{Bk} . \quad . \quad \text { (V) }
\end{array}
$$

These equations agree (accidentally, to some extent, no doubt) with the following, which was determined by a single observation:

$$
180 \mathrm{R}+180 \mathrm{~B}=133 \mathrm{R}+60 \mathrm{~W}+167 \mathrm{Bk} .
$$

Of course the equations (IV) and (V) would give, in conjunction with (I) or (II), an expression for red in terms of a mixture of black and white. They must not be used in that way, because of the fact that green and blue light, though they are equivalent to grey in regard to colour sensation, are not equivalent to a mixture of black and white in regard to complementariness to red.

The yellow disc was also matched with a mixture of black and white, thus

$$
\left.\begin{array}{l}
360 \mathrm{Y}=295 \mathrm{~W}+65 \mathrm{Bk} \\
360 \mathrm{Y}=258 \mathrm{~W}+102 \mathrm{Bk}
\end{array}\right\} . . . .(\mathrm{VI})
$$




\section{Contrast Tests.}

A white screen was illuminated by light from two sources-one coloured, the other white-and thus two images of an object, coloured with complementary colours, were thrown side by side on the screen. The first column gives the name of the coloured light and of one shadow; the second gives the colour of the other shadow. The results, as given by $\mathrm{Mr} \mathrm{A}$., are put in brackets alongside.

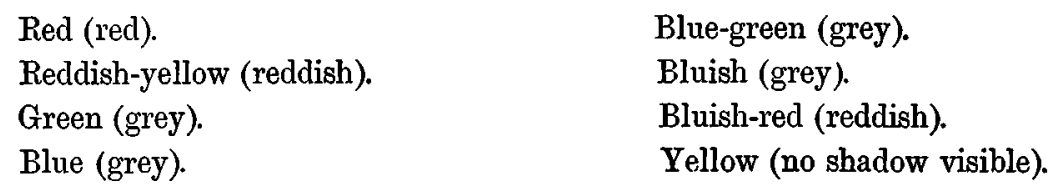

Again, coloured discs, having the same colours as those which were used in the disc tests, were placed on a white background, and were suddenly withdrawn after they had been gazed at for some time. When a green disc was used, Mr A. saw distinctly the reddish after-image. When red, blue, and yellow discs were used, he saw no after-image.

In this way it is proved that the green colour, though it was grey to him, could yet produce the complementary red colour by contrast.

\section{Spectrum Tests.}

Colour Nomenclature.- Mr A. was shown a patch of practically monochromatic spectrum colour and was asked to describe its appearance. The results are given below, the normal terms being in the left-hand column and Mr A.'s in the right-hand column.

Dark red
Bright red
Orange-red
Reddish-yellow
Slightly reddish-yellow
Yellow
Very yellow-green
Yellow-green
Green
Bright blue-green
Blue
Strong dark blue
Violet
Dark violet
Very dark violet
Darkest visible violet

Dark red.

Bright red.

Red.

Warm white.

Less warm white.

White.

White.

Very nearly grey (mixed with something).

Very nearly grey (mixed with something).

Greyish.

Grey.

Grey (darker than last).

Dark grey.

Darker grey.

Still darker grey.

Very dark grey (no red). 
Mr A. at first said that he knew the difference between green and blue and that he could distinguish them, but it was easy to prove to him that he could not do so. When asked to name the colour, he was as often wrong as right. So that it is very questionable if the statement " mixed with something" is of much value.

Spectrum Matches. - Two patches of monochromatic light were looked at side by side. While one was always yellow, the colour of the other was varied at pleasure. The intensity of either could be altered until it was equal to that of the other. In this way Mr A. matched with yellow, more or less darkened, all the colours yellow-green, green, bluegreen, blue, indigo, and violet, to the extreme end of the spectrum. I then, unknown to Mr A., changed the yellow patch to dark red, and, making it almost invisibly dark, made the other patch violet, and asked him to adjust them to equality. He at once said that it was impossible to do so as the one was red. 'The same result happened when the dark red patch was made a yellow-red and was darkened. He asserted that he never saw red in spectrum violet.

As in the previous observations, Mr A. said that he was thoroughly satisfied in calling all the first-mentioned colours greys, with the exception of green and blue-green, which he said made a somewhat unsatisfactory match with yellow, though I did not find that the unsatisfactoriness was sufficient to enable him to distinguish green from blue. Nevertheless I believe that it indicates that the green sensation is very nearly appreciated.

Superposition of Spectrum Colours.-The first and second columns contain the names of the superposed colours, and the third column contains the name of the mixture. The names used by $\mathrm{Mr} \mathrm{A}$. are in all cases given in brackets.

$\begin{array}{lll}\text { Red (red). } & \text { Green (grey) } & \text { Yellow (white). } \\ \text { Red (red). } & \text { Blue (grey). } & \text { Grey (grey). } \\ \text { Yellow (white). } & \text { Dark blue (grey). } & \text { Grey (grey). } \\ \text { Yellow-green (grey). } & \text { Indigo (grey). } & \text { Blue (grey). } \\ \text { Green (grey). } & \text { Violet (grey). } & \text { Blue (grey). }\end{array}$

Comparison with the case described by v. Vintschgau and Hering.

The experimental investigation of this case is given very fully by v. VINTSCHGAU in Pflüger's Arch.f. d. ges. Physiol., Bd. 48, s. 43, and Bd. 57, s. 191. Hering's discussion is given in Bd. 57, s. 308 of that journal. There was great reduction in the intensity of light from the normal value and the spectrum was much shortened at both ends. Roughly speaking, red light began to be visible about half-way between the lines $\mathrm{C}$ and $\mathrm{D}$ and vanished before $\mathrm{D}$ was reached. The spectrum was colourless from the latter point until the yellow-green part was reached. This part was called "yellow." The rest was called "green," up to a point slightly beyond F, then all colour again vanished, and all light disappeared before the line $\mathrm{G}$ was reached. 
HeRING proved that this case was a distinct case of blindness to yellow and blue with a neutral point in the yellow part of the spectrum and another in the blue part. He also proved that, though the light adjacent to this second neutral point was termed colourless, the light on the less refrangible side possessed a green valency, while the light on the more refrangible side possessed a red valency.

In Mr A.'s case, the reduction of intensity, if it occurs at all, is so slight that the spectrum is visible to its full extent. The red part is visible over its whole normal range, and no colour is visible in any other portion.

\section{Conclusion.}

Mr A.'s case is, strictly speaking, one of blindness to all colours except red. Yet it is not a case of monochromasy. It seems to be strictly a case of dichromasy, for all the tests show that there is a true neutral point in the yellow part of the spectrum, and that the colourless light of the green and blue parts is complementary to the red. I cannot certainly say as yet that there is no second neutral point in the blue part of the spectrum, but I have not got the slightest evidence of it or of the existence of a red valency in the violet region. Yet $\mathrm{Mr} \mathrm{A}$. seems to possess the full normal sensitiveness to red. He can detect the existence of red in white or black apparently quite as soon as an observer who possesses normal vision can. $\mathrm{He}$ can distinguish the various shades of red and name them correctly-marone, scarlet, strawberry, \&c., and even pink. Of course, in the latter case, he might be deceived by a red mixed with grey instead of blue. Yet, as I have stated, he has never shown any tendency to speak of the violet light of the spectrum as red. Still, the point is not decided, and I intend to investigate it further.

The fact that the violet end of the spectrum is unshortened precludes the case from being described as the "violet-blindness" of the unmodified Young-HeLmholtz theory. Yet the neutral point in the yellow is in agreement with that description. In " partial green blindness," on this theory, the spectrum has its full length, and, though a large part of the green portion may be grey, the blue is visible. The immense differences in the appreciation of red and green, laying aside the question of a second neutral point, tell against the application of Hering's theory. In any case, the modern modification of the YounG-Helmholtz theory can apply. I have already given a discussion of the bearings of the case on the theories, but I defer its publication until the experimental investigation is completed.

It is interesting to compare the case with the only genuine case of "violet-blindness" which Captain ABNEY has met (up till 1895). In the latter, the spectrum was shortened at the violet end and there was a neutral point in the yellow part. Only two colours were named-red and black. Green was called "bright-black," though it did not satisfactorily match a darkened white patch. Blue was called "dark-black." Suppose 
the spectrum to be extended to its normal length, substitute the word "grey:" for " black," and we have Mr A.'s case.

I append some illustrations of Mr A.'s colour matches. All matches are placed together in columns-four matches in the left-hand column, four in the central column, and two pairs of matches in the right-hand column. Though he sees no difference in colour between the members of the upper pair in the last column, $\mathrm{Mr}$ A. can readily distinguish them, and describes the one with a blue tinge as having a dirty or washedout appearance. 


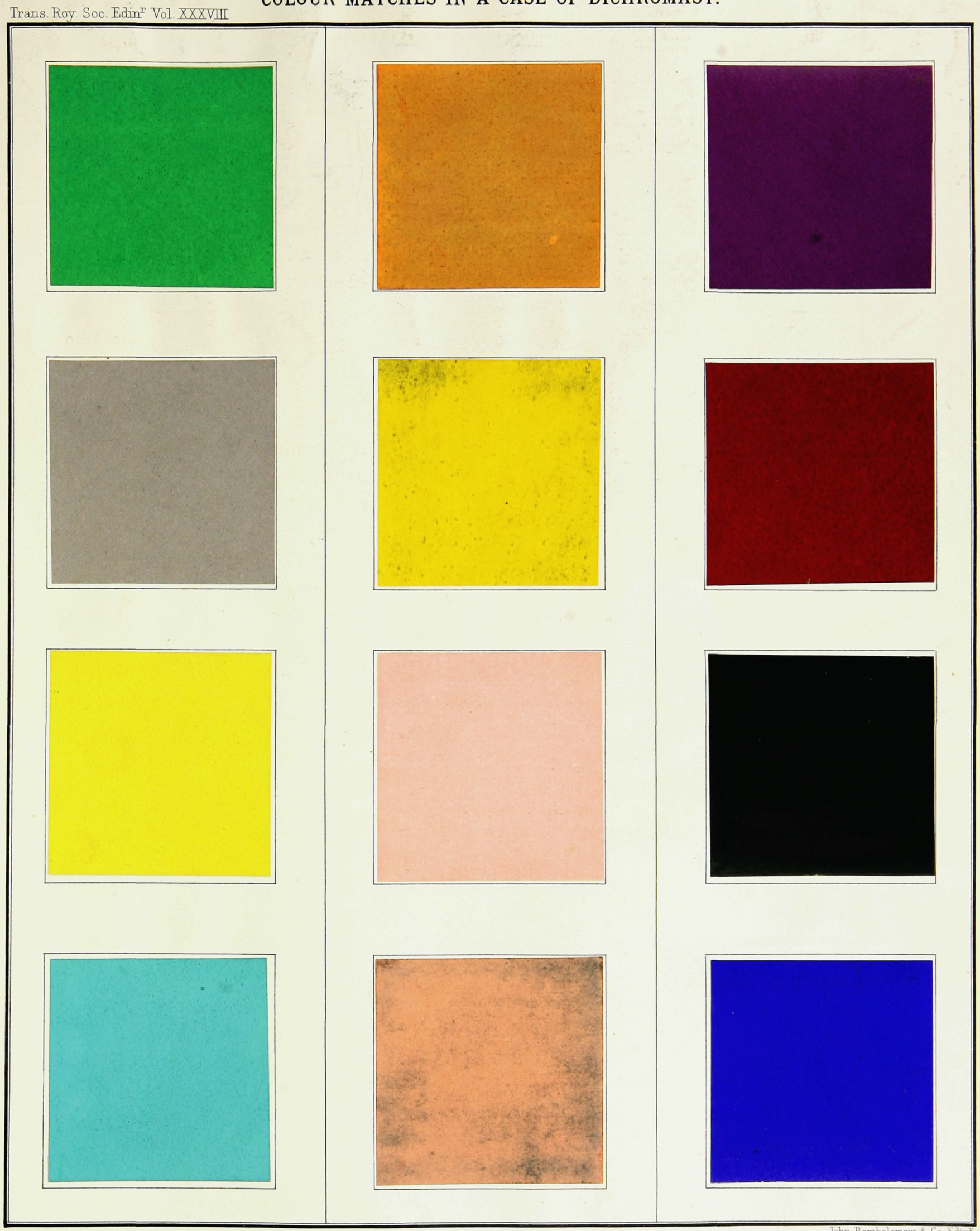

